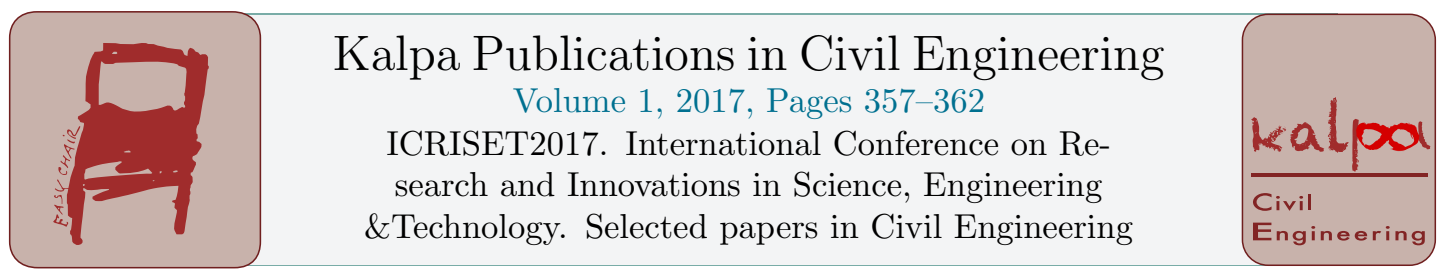

\title{
Land Suitability Analysis for UrbanPlan Preparation Using Remote Sensing and GIS A Case of Anand-Vidyanagar-Karamsad Development Plan \\ Mehul Darshak ${ }^{1}$, Manthan Bhandari ${ }^{2}$, Rajansinh Zala ${ }^{3}$, Prof. (Dr.) Shashikant Kumar ${ }^{4}$
}

${ }^{1}$ Assitant Professor,D.C.Patel School of Architecture,APIED, Campus,V.V.Nagar, India ${ }^{2}$ Assistant Professor, Architecture Department, Laxmi Institute of Architecture, Sarigam, India.

${ }^{3}$ Visiting Faculty, Bhaikaka Cetnre for Human Settlement, APIED, Campus, V.V.Nagar, India

${ }^{4}$ Principal, Bhaikaka Cetnre for Human Settlement, APIED, Campus, V.V.Nagar, India

\begin{abstract}
Land Suitability analysis is important for preparation of Development Plan. The planning requires undertaking study of topography, water resources, land utilization, and development needs. The RS \& GIS techniques offers suitable analytical opportunity to study variables required for selection of sites for various uses. This paper presents process adopted for the preparation of development plan of Anand Vidyanagar Karamsad Urban Development Authority (AVKUDA), regarding the land suitability analysis. The location and types of land to be protected were identified using RS Data and GIS analysis. Keywords - AVKUDA; Land Suitability; Planning; RS \& GIS
\end{abstract}

\section{Introduction}

Suitability: Slope analysis and its impact especially on drainage, sewerage, water supply, rainwater harvesting system, etc. Natural Drainage and water bodies,Sunlight and wind direction analysis. Geology soils and ground water status. Ground cover- parks, open spaces, forest, orchards, green bells, etc. 


\section{Compatibility of the land}

A. Compatibility of the land use was analysed for existing strength, weakness, opportunity and threat analysis for the sites. The matrix based decision logic was chosen for the conceptual proposals. The compatible uses were placed accordingly. The analysis also included the extension of the current uses and rejection of certain non-compatible uses in earlier development plans.

B. The planning mechanism involved the discussion with stakeholders which was undertaken in two stages before and after the initial plan preparation. The key stakeholders which include the decision makers at the urban local bodies and authority itself were shown the conceptual plan and discussion on key proposals took place. The proposal were also discussion with the state and region level town planning officials and their opinion also were incorporated in the proposed plan. However, the plan expects inputs from the general public before being finalized in coming next stage.

C. Identification of Natural Hazards Areas and Protected Zones

Flood Hazard: The most common hazard in the region is due to excessive rainfall and poor management of the drainage network. The water bodies within the AVKUDA region is poorly managed leading to encroachments, dumping of solid waste, and reduction in natural areas. The increasing runoff due to increase in impervious surface leads to accumulation of water in the low lying areas.

Double cropping area: AVKUDA is part of the great grain producing Charotar region, considered as one of the productive belts of the Central Gujarat. Out of the 33 villages within the authority area about 50 percent of the villages have large tracts of land under the agricultural crop. In these villages about 70 percent of the working population is dependent upon the primary sector. Nearly 30 percent of population an estimated 2.2 lakh persons are dependent on the agricultural income only. The villages like Adas, Mogar, Samarkha, Jhakaria, Jol, Boriya, Rajupura, Anklawadi, Gopalpura, Gana, etc are dependent on agriculture. Many villages like Navli, Napad Talpad, Napad Vanto, Hadgud and Adas also has agro-based industries and infrastructure which are likely to be remain so in next ten years. The prospective land holders with irrigation facilities from Mahi canal and other sources are cultivating double crop per year. [3]

\section{Methodology and Data}

The land suitability analysis was done for the selected project area of AVKUDA covering 282 sq. kms. The data were sourced from the open sources such as Bhuvan (ISRO), USGS and others from their websites. The sources were used data in formats available such as tiff, geotiff., etc. The data is used with minimal correction with following steps (a) Scanning of Cadastral Maps and digitization (Vector data) (b) Processing RS Imagery (ASTER and LISS-III) (c) Joining of attribute data with vector data. Fig. 1 and Fig. 2 shows the Work Flow for preparing Base Map. 


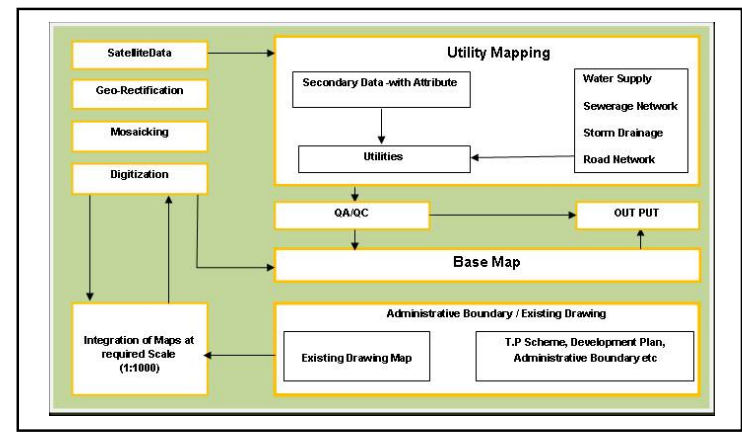

Fig. 1: Workflow of Base Map preparation

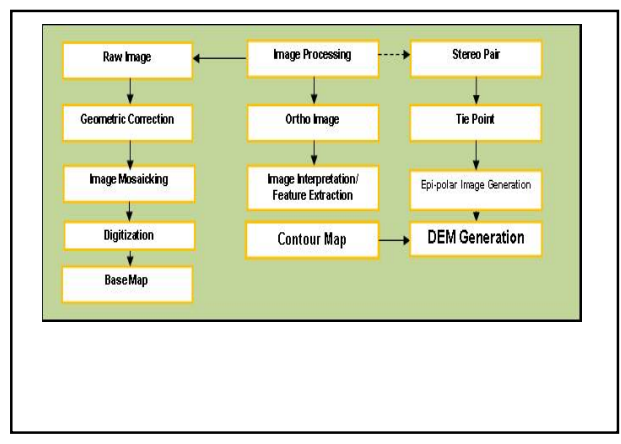

Fig.2: Base Map preparation

Latest available LISS-III data and ASTER data for download were used. The cadastral maps available with revenue department were digitized. Data for land use up to 2013 available with revenue department was used.

\section{LISS DATA}

The Linear Imaging Self Scanning Sensor (LISS-III) is a multi-spectral camera operating in four spectral bands, three in the visible and near infrared and one in the SWIR region, as in the case of IRS-1C/1D. The new feature in LISS-III camera is the SWIR band (1.55 to 1.7 microns), which provides data with a spatial resolution of $23.5 \mathrm{~m}$ unlike in IRS-1C/1D (where the spatial resolution is 70.5 m).[1] Fig. 3 shows the False Color Composite (FCC) created from LISS-III Data.

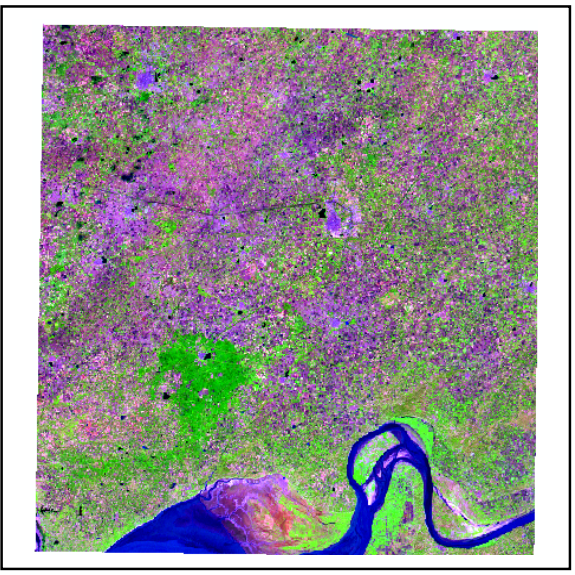

Fig. 3 False Color Composite created from LISS III Band Data*

\section{ASTER DATA}

The Advanced Space borne Thermal Emission and Reflection Radiometer (ASTER) is an advanced multispectral imager that was launched on board NASA's Terra spacecraft in December, 1999. ASTER covers a wide spectral region with 14 bands from the visible to the thermal infrared with high spatial, spectral and radiometric resolution. An additional backward-looking near-infrared band provides stereo coverage. The spatial resolution varies with wavelength: $15 \mathrm{~m}$ in the visible and nearinfrared (VNIR), $30 \mathrm{~m}$ in the short wave infrared (SWIR), and $90 \mathrm{~m}$ in the thermal infrared (TIR).

"(Band 5 (Red), Band 4 (Green), Band 3 (Blue)) (Note: Downloaded from http://bhuvan.nrsc.gov.in/data/download/index.php, L3_SAT_8B_V1_72.75E22.5N_f43g14_01nov08.zip downloaded on 26/02/2013) 
Each ASTER scene covers an area of $60 \times 60 \mathrm{~km}$.[2] Fig. 4 shows the ASTER data tile of the study area.

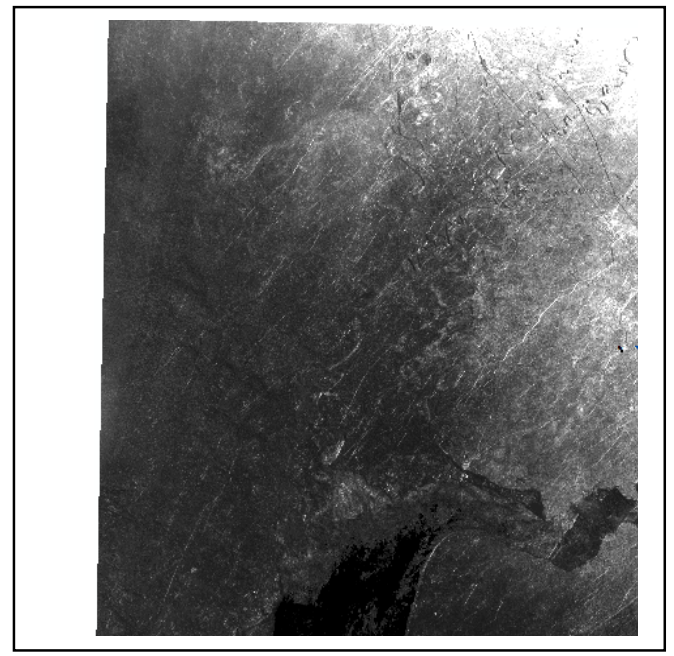

Fig. 4 ASTER Data ${ }^{\dagger}$

Spatial and Attribute Data Processing

The images are used to generate thematic information - the Repository Content and the thematic maps also need to be as per defined standards. If the GIS database is standardized, then extracting outputs and providing services will also be possible. Spatial data of Cadastral maps, LISS - III data for Land use Land Cover and Processed ASTER data is overlaid to identify developable and nondevelopable area based on physical features and land use.

Data regarding land use and cropping is collected from revenue department this attribute data is used to identify and validate double cropping area and statutory water bodies. Also the natural drainage pattern and creek areas are identified for protection.

\section{Integration of GIS/RS Data}

- Assessment of all required inputs for developing GIS database for the project area.

- Collection and collate of data (LISS-III, Cadastral and ASTER) from different departments, agencies and websites.

- Geo-referencing of Cadastral Map.

- Digitization of base map features and contours from department maps (Base maps are in form of *.dwg and it consists of Town Planning Schemes, Revenue Survey Number, Block No., Census Survey Number, Ward Number, etc.).

- Digitization of high-resolution satellite images to update the base map features.

- Development/Integration of attribute data with digitized features in the GIS Database.

- Integration of high-resolution satellite images with GIS Database.

- Integration of Town Planning scheme / Development plans with GIS Database.

- Creation and categorization of land suitability matrix, from existing database.

\footnotetext{
† ASTER Data Downloaded from https://asterweb.jpl.nasa.gov/data.asp ASTGTM2_N22E072.zip Downloaded on $27 / 02 / 2013$
} 
This has resulted in competency of land parcel for development with different land use and same is considered while assigning land use to the parcels. Fig. 5 shows the flow chart of integration of Remote Sensing and GIS data base

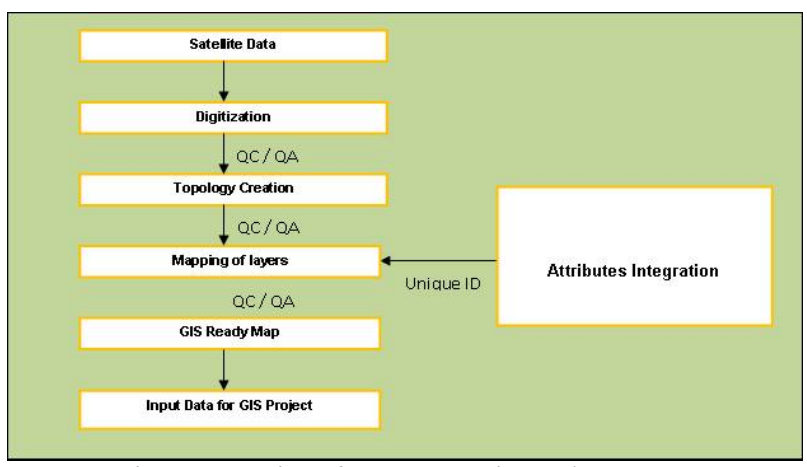

Fig. 5 Integration of Remote Sensing and GIS Data

\section{RESULTANT THEMATIC MAPS}

For citations it is recommended that you use the bibliography mechanisms of Microsoft Word or other tools able to process docx documents. In Microsoft Word, commands for inserting citations are located at the Document Elements tab of the ribbon control in the section References. Clicking the

The following results were derived from the data processing using the open source RS/GIS software. Fing 6 is result of the ASTER Data processing and shows the Elevation profile of the Anand Urban Agglomeration

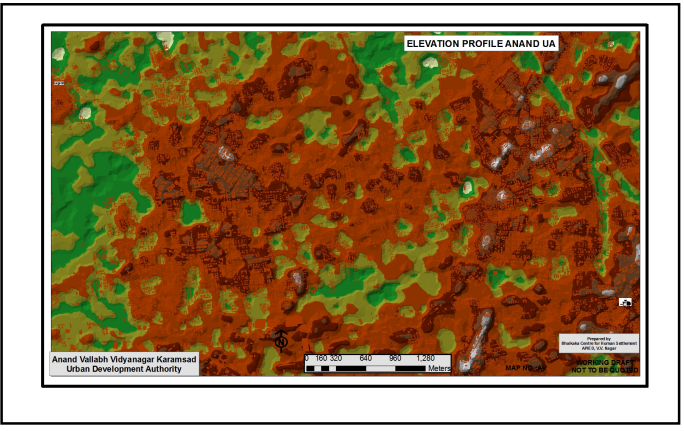

Fig.6 Elevation Profile of Anand Urban Agglomeration Agglomeration

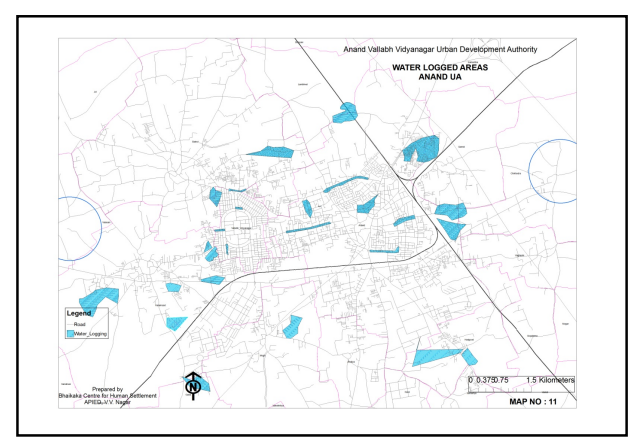

Fig. 7 Water Logged area in Urban

Fig 7 shows the area prone to water logging same is confirmed during field visits and interviews with officials and citizens. 
Land Suitability Analysis - A Case of AVKUDA M. Darshak, R. Zala, M. Bhandari \& Dr. S. Kumar

Table 1: Existing Land Use AVKUDA (2013)

\begin{tabular}{|c|c|c|c|c|c|c|c|}
\hline \multicolumn{8}{|c|}{ Existing Land Use AVKUDA (2013) } \\
\hline CLASS & Anand & Bakrol & VVN & Mogri & Karamsad & Other villages & TOTAL \\
\hline Agriculture & 536.56 & 1422.88 & 0.14 & 638.47 & 1224.48 & 16755.88 & 20578.41 \\
\hline Commerial & 93.05 & 3.03 & 10.00 & 12.51 & 12.14 & 124.08 & 254.80 \\
\hline Gamtal & 0.00 & 27.42 & 0.00 & 13.39 & 20.50 & 259.09 & 320.39 \\
\hline Industries & 19.54 & 0.00 & 0.00 & 77.14 & 171.49 & 91.31 & 359.48 \\
\hline Public Purpose & 380.23 & 15.13 & 48.36 & 23.60 & 36.45 & 185.73 & 689.50 \\
\hline Public Utility & 74.33 & 3.52 & 21.79 & 3.35 & 44.68 & 63.99 & 211.66 \\
\hline Residential & 778.57 & 216.15 & 100.23 & 47.20 & 203.95 & 872.48 & 2218.59 \\
\hline Transport & 224.50 & 52.50 & 28.71 & 10.22 & 89.32 & 1165.91 & 1571.16 \\
\hline Vacant & 0.00 & 0.22 & 0.28 & 0.00 & 0.00 & 252.07 & 252.57 \\
\hline Waterbody & 23.07 & 29.07 & 0.00 & 27.83 & 27.49 & 643.83 & 751.29 \\
\hline Total & 2129.84 & 1769.92 & 209.52 & 853.70 & 1830.50 & 20414.38 & 27207.86 \\
\hline
\end{tabular}

The area of double cropping is identfied and selected as a last option for land use change. Fig 8 shows the double cropping areas in AVKUDA region.

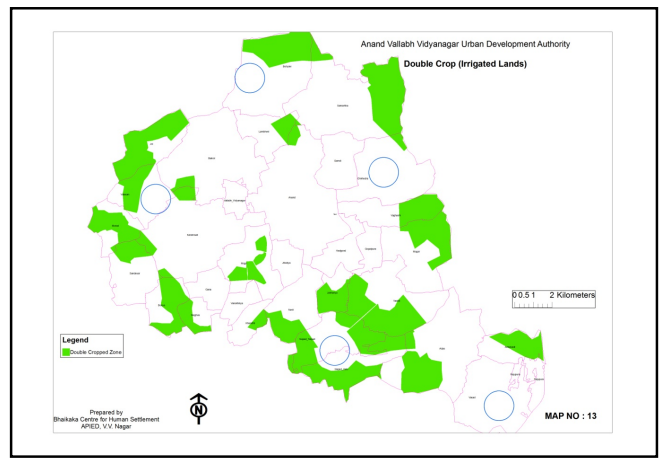

Fig.8 Double cropped area

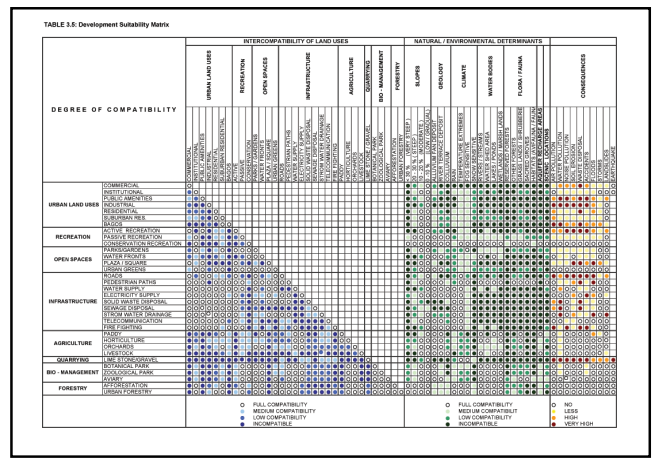

Fig.9 Land Suitability Matrix

Using Land use compitability parameters and actual situation of zones land suitability matrix is developed. Fig. 9 shows the land suitability matrix for AVKUDA region.

\section{Conclusion}

The results of this analysis were used to allocate the final land use for the study are generated. The remote sensing data can be used to generate the thematic maps apart from the topographic information, hydrological mapping and land use. The land suitability matrix prepared after generating the thematic maps, using overlay techniques of GIS. The resultant draft development plan was presented to the authority after conducting extensive public consultation. The focus of the technology here is to apply the techniques of RS/GIS to suit to policy requirements and concerns of the development authority. We hope the efforts on our team would inspire the researchers to continue to conduct similar exercise.

\section{References}

[1] Compiled by NRSA Data Center, IRS-P6 Data User's Handbook, IRS-P6/NRSA/NDC/HB-01/04 January 2004, pp. 12

[2] Michael Abrams, Simon Hook, Jet Propulsion Laboratory and Bhaskar Ramachandran, EROS Data Center ASTER Data User Handbook, Version 2. JPL \& NASA, pp.8.

[3] AVKUDA, “Draft Development Plan Report 2033” Unpublished Report, 2014. 